\title{
LETTER
}

\section{To transfuse or not to transfuse: thinking outside the box}

\author{
Yasser Sakr* and Konrad Reinhart \\ See related commentary by Walsh, http://ccforum.com/content/14/3/170, and related research by Sakr et al., http://ccforum.com/content/14/3/R92
}

The commentary by Dr Walsh [1] discussed our study in a systematic way and highlighted several important aspects in relation to our analysis. Indeed, our study has limitations that we acknowledged in our paper. It should be noted, however, that the Transfusion Requirements in Critical Care (TRICC) study [2] excluded cardiac surgical patients and patients who had received blood transfusions before ICU admission. Thus, surgical patients who received intraoperative transfusions were probably excluded. The results of the TRICC study may not, therefore, be extrapolated to surgical ICU patients. Hence, we do not agree with Dr Walsh that the current evidence is consistent with hemoglobin triggers less than $9 \mathrm{~g} / \mathrm{dL}$ in surgical ICU patients. In the absence of large cohort studies and randomized controlled trials in this specific subgroup of ICU patients, the results of our study should be considered relatively robust pending the results of future randomized controlled trials. We agree with Dr Walsh, however, that more TRICCs are needed, hopefully designed to include different case mixes and avoiding the 'one size fits all' concept. It may also be necessary to think outside the box. Hemoglobin levels are not the only determinant of oxygen delivery to the tissues and are not expected to reflect tissue perfusion or cellular metabolic needs. A successful transfusion strategy should consider all these factors and should not be minimized to the simple question, 'which hemoglobin level should be targeted?' but to the more relevant question 'could this specific patient benefit from blood transfusion in this specific clinical situation?'

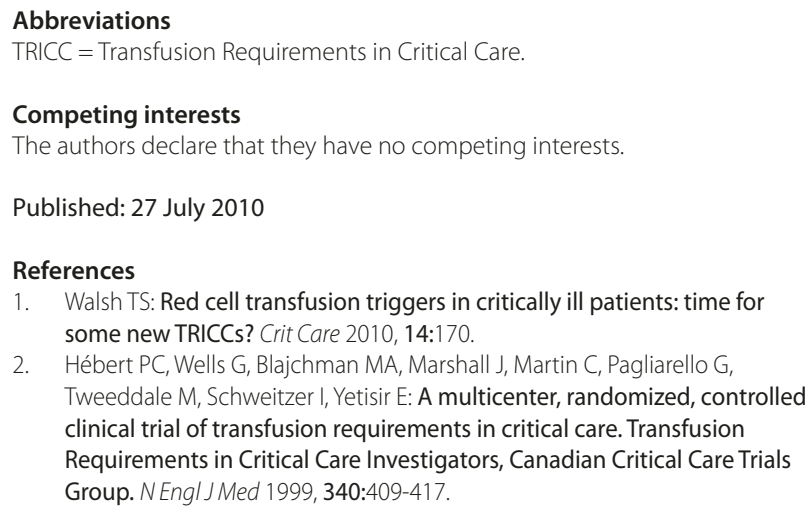

Published: 27 July 2010

\section{References}

1. Walsh TS: Red cell transfusion triggers in critically ill patients: time for some new TRICCs? Crit Care 2010, 14:170.

2. Hébert PC, Wells G, Blajchman MA, Marshall J, Martin C, Pagliarello G, Tweeddale M, Schweitzer I, Yetisir E: A multicenter, randomized, controlled clinical trial of transfusion requirements in critical care. Transfusion Requirements in Critical Care Investigators, Canadian Critical Care Trials Group. N Engl J Med 1999, 340:409-417.

doi:10.1186/cc9183

Cite this article as: Sakr Y, Reinhart K: To transfuse or not to transfuse: thinking outside the box. Critical Care 2010, 14:431.
*Correspondence: yasser.sakr@med.uni-jena.de

Department of Anesthesiology and Intensive Care, Friedrich Schiller University Hospital, Erlanger Allee 103, 07743 Jena, Germany 